\title{
Bachem, a Swiss Speciality cGMP-Manufacturer: History and Future Prospects
}

\author{
Thomas Vorherr, Fritz Dick, and Beat Sax
}

\begin{abstract}
This article summarizes the development of the Bachem Group and the ongoing commitment regarding its production facilities in Switzerland. Bachem's core business, the manufacture of peptides from lab scale to market quantities, is explained using showcases to detail the high level of know-how needed to successfully prepare very large biomolecules. Based on these examples, the complexity regarding production processes and allocation of manufacturing sites are elucidated.
\end{abstract}

Keywords: Bachem · cGMP-manufacturing · Peptides

Bachem was founded in 1971 by Peter Grogg who, at that time, had realized the market potential of peptide derivatives as substrates and inhibitors for various enzymes. Due to negligible competition and a growing demand from the market, academic institutions, and industries, the business was profitable from its first year on. Soon, this rapid development required a location with sufficient room for future growth. Such a site was found in Bubendorf in the vicinity of Basel, thus very close to the pharma companies with access to chemists graduating from Basel and Zürich Universities, and availability of a sufficiently large piece of land to support growth for the coming years.

In the following years competition grew, however at the same time, the strategic move into cGMP-manufacturing of

${ }^{\star}$ Correspondence: Dr. T. Vorherr

Bachem Holding AG

Hauptstr. 144

$\mathrm{CH}-4416$ Bubendorf

Tel.: +41619352448

Fax: +4161935 2324

E-Mail: Thomas.vorherr@bachem.com peptides as bulk pharmaceuticals secured Bachem's leading position up to the present day. The product structures to be synthesized became more complex and, nowadays, even proteins up to 100 amino acids are amenable to chemical synthesis under cGMP-conditions at Bachem. Highly skilled chemists and technicians, enabling Bachem to carry out applied research in-house and to move forward general methodology in the peptide area, represented the prerequisites to appropriately address a development of manufacturing methodology.

This development was accompanied by continuously building up a strong quality assurance and a regulatory affairs group. Combining the excellence in production with an expert service can be viewed as a logical strategic step to strengthen the leadership in the field of cGMP-manufacturing. Accordingly, the qualified support for registration purposes encouraged clients from the biotech and pharma environment to enter into clinical trials with peptides from Bachem. As a consequence of these efforts, 65 national European Drug Master Files (EDMF) have been approved, and 35 US Drug Master Files (DMF) are active. Furthermore, several DMFs are active in other countries and numerous technical packages have been submitted in support of successful Clinical Trial Exemption (CTX) and Investigational New Drug (IND) applications.

As indicated above, the focus of recent demand has shifted to more complex molecules. For the two main approaches in peptide chemistry, solution-phase and solid-phase synthesis, some more details for two established cases, Calcitonin and Glucagon (Fig. 1), are described to highlight the complexity and hence the knowhow involved in process development and manufacturing (Table).

Historically, the production of larger amounts of peptides has been accomplished by solution-phase methods, since this process provides options for purification of the intermediates and scale-up, as outlined in the synthesis scheme for Calcitonin (Fig. 2).

Production up to the multi-ten $\mathrm{kg}$ level has been achieved and hundreds of $\mathrm{kg}$ of Luteinizing Hormone-Releasing Hormone (LHRH)-analogues have been manufactured in Bubendorf. Experience in running the reactions, facilitation of work-up and purification is required to be able to optimize this complex process. In addition, a prolonged lead time (see Table) and detailed knowledge is essential to reproducibly achieve high quality. As a consequence, transfer to other sites or countries presents problems especially regarding sophisticated steps like the crystallization of intermediates.

The progress in solid-phase technology, originally described by R.B. Merrifield who received the Nobel prize for this invention in 1984 [1], seemed to lead to mitigation of these problems. In particular since synthesis of complicated structures on solid supports, without the need to be concerned about intermediates, has been successfully reported. Clearly, the simplicity of the method and the speed represent the advantages of this alternative strategy 


\section{Calcitonin (salmon I)}

\section{S N L S T C V L G K L S Q E L H K L Q T Y P R T N T GS G T P NH}

\begin{tabular}{|l|l|l|l|l|}
\hline $1-6$ & $7-10$ & $11-16$ & $17-23$ & $24-32$ \\
\hline
\end{tabular}

\section{Glucagon (1-29, human)}

\section{H S Q G T F T S D Y S K Y L D S R R A Q D F V Q W L M N T}

Fig. 1. Sequences (one letter code) of Calcitonin and Glucagon including a schematic representation of fragments used for Calcitonin synthesis

Table. Comparison of production: Calcitonin (solution-phase) - Glucagon (solid-phase)

\begin{tabular}{|c|c|c|}
\hline Characteristics & Calcitonin & Glucagon \\
\hline Produced since & 1986 & 1996 \\
\hline $\begin{array}{l}\text { Synthesis }{ }^{a} \text { : } \\
\text { Number of steps }{ }^{b}\end{array}$ & 62 & 32 \\
\hline $\begin{array}{l}\text { Purification }{ }^{\mathrm{a}} \text { : } \\
\text { Number of steps }\end{array}$ & 20 & 60 \\
\hline Purification & $\begin{array}{l}\text { counter current distribution } \\
\text { two-dimensional HPLC }\end{array}$ & three-dimensional HPLC \\
\hline $\begin{array}{l}\text { Derivatives needed for } \\
\text { production of } 1 \mathrm{~kg}\end{array}$ & $158 \mathrm{~kg}$ & $29 \mathrm{~kg}$ \\
\hline $\begin{array}{l}\text { Time for completion of one } \\
\text { entire synthesis }^{b}\end{array}$ & 2.5 years & 0.6 years \\
\hline
\end{tabular}

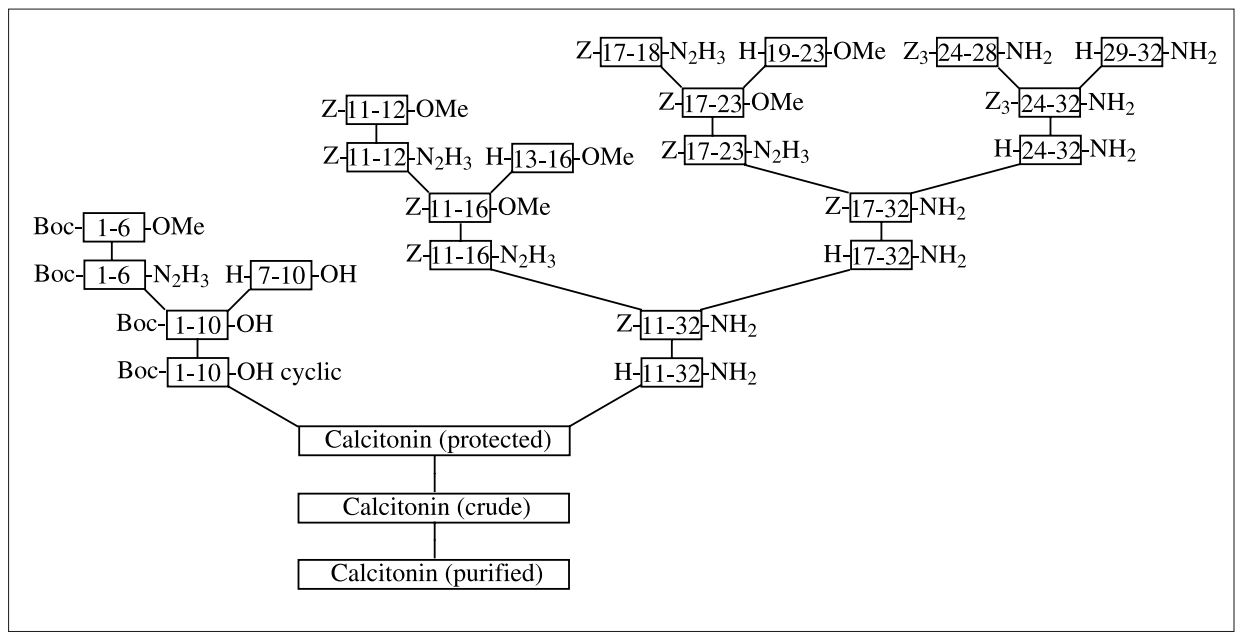

Fig. 2. Solution synthesis scheme for Calcitonin (salmon I) and a growing body of improvements in protecting group- and coupling-chemistry has further facilitated the application of solid-phase peptide synthesis. For a matter of comparison, key figures of Bachem's solid phase process for $\mathrm{kg}$-quantities of Glucagon (Table) are provided to contrast those for the solution-phase synthesis of Calcitonin. However, the following aspects have to be considered when entering a comparative evaluation solid-phase versus solution-phase synthesis.

Although the solid-phase process is far more robust and faster, and thus easier to transfer, in-depth knowledge of peptide chemistry is required if problems during synthesis occur. Savings during the development of the synthesis must be carefully compared to the increased efforts needed to establish an effective purification program utilizing expensive chromatographic equipment. Generally speaking, the shorter the peptide and the higher the quantities the more likely it is that a solution-phase process is implemented. Since the 'limits' have been shifted considerably towards solid-phase chemistry, the majority of new projects involve solid-phase synthesis procedures, particularly, when structures are complex and time is limited.

Bachem's own R\&D efforts, like the work on extremely acid labile resins [2], his incorporation [3] or efforts to reduce aspartimide formation [4] have been published or presented at scientific meetings. This work has considerably contributed to improve production efficiency. In the case of Glucagon, most of the solutions to problems identified during up-scaling had to be developed in-house since published papers did not provide the necessary details. Examples in this context relate to prevention of incomplete Fmoc-cleavages, improvements on Asn/Gln side-chain protection, optimization of cleavage protocols and facilitating solubility for purification.

Another example in the category of solid-phase synthesis products is represented by the malaria vaccine project, AMA49-CPE (Fig. 3), which was brought forward by Pevion Biotech, a joint-venture of Bachem and Berna Biotech. In this case, a solid-phase process for a 49 residue cyclic peptide carrying a lipid anchor for insertion in the delivery vehicle, the virosomes, had to be established to be able to rapidly enter phase I clinical trials. Improvements on the standard procedure were mandatory, and problems related to incorporation of succinic acid, the phospholipid building block and cyclization could only be solved in a timely manner due to focused $R \& D$ activities. In this program, coupling procedures have been optimized and as a result an elaborated method has been developed which led to a significantly improved quality for the active AMA49-CPE ingredient. 


\section{(1,3-Dipalmitoyl-glycero-2-phosphoethanolamine)-succinyl-}

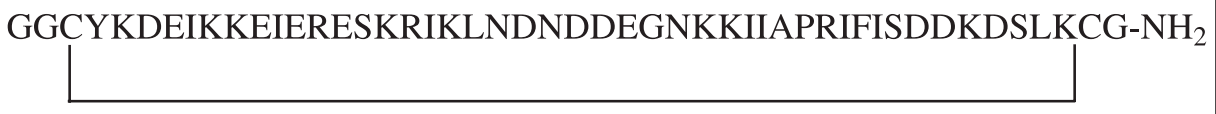

Fig. 3. Structure and sequence (one letter code) of the malaria vaccine AMA49-CPE

As illustrated with this malaria vaccine example, advances in science and technology are reflected in a growing demand for more sophisticated molecules. This phenomenon is associated with the ambition to systematically improve selectivity and potency for future drugs. Consequently, the trend towards investigation of complex structures has an impact on the final compounds to be manufactured under cGMPconditions.

Due to this tendency towards enhanced complexity and requests for integrated expert services, Bachem keeps its commitment to the location in Bubendorf, having built yet another production building three years ago. This structure permits stepwise expansion to triple the current peptide production capacity in Switzerland.

The proximity to important clients represents a key to success. The disadvantage of Switzerland not being a member of the EU has been addressed by establishing a new logistic organization. This understand- ing, to enable close interaction with customers and provide fast service, has also been one of the reasons to expand into the US market, first by forming a subsidiary in Philadelphia and then by acquisition of the cGMP-site Bachem California in 1996. Similarly to the situation in Switzerland, the environment of our US subsidiaries constitutes the basis to drive a challenging business successfully forward; however the limited availability of technically skilled ment in training.

Another acquisition in Switzerland was accomplished in 2001. Among other reasons, Sochinaz was bought to enable scaleup of peptide manufacturing to ton quantities. Currently, this affiliation produces small molecular weight generic compounds and thus, is more vulnerable to competition from far eastern countries. Nevertheless, a proper long-term planning, the right choice of target, a stringent process development, a high degree of reliability and a high qualpersonnel requires a considerable invest- ity of products including the corresponding documentation represent the key factors to succeed in 'Time to Market' and, finally, to keep this business prosperous in a more competitive setting.

In conclusion, production facilities in Switzerland will continue to be expanded with the increase in Bachem's core business, peptide manufacturing. Since there is a growing need for expert synthesis of complicated structures and the corresponding unique technologies, including processes, can be readily adapted to the dynamics of the environment, Bachem is well positioned to take advantage of these developments. After all Bachem is a Swiss company and, therefore wants to contribute to Swiss economy and society, e.g. by generating workplaces including apprenticeships.

Received: November 2, 2004

[1] R.B. Merrifield, Angewandte Chemie Int. Ed. 1985, 24, 799.

[2] M. Mergler, J. Gosteli, P. Grogg, R. Nyfeler, R. Tanner, Chimia 1999, 53, 29.

[3] M. Mergler, F. Dick, B. Sax, J. Schwindling, T. Vorherr, J. Peptide Sci. 2001, 7, 502.

[4] M. Mergler, F. Dick, B. Sax, P. Weiler, T. Vorherr, J. Peptide Sci. 2003, 9, 36; M. Mergler, F. Dick, B. Sax, C. Stähelin, T. Vorherr, J. Peptide Sci. 2003, 9, 518. 